\title{
Glare and Contrast Sensitivity in Contact Lens Corrected Aphakia, Epikeratophakia and Pseudophakia
}

\author{
R. A. HARPER and B. L. HALLIDAY \\ London
}

\begin{abstract}
Summary
The effects of glare on contrast sensitivity and high contrast Snellen acuity were investigated in a group of unilaterally aphakic patients with normal fellow eyes. In spite of relatively good visual acuity and apparently satisfactory surgical results, there was a marked reduction in contrast sensitivity in epikeratophakia and contact lens corrected aphakic eyes, relative to fellow normal eyes, especially in the presence of glare $(\mathbf{P}<\mathbf{0 . 0 5})$. Although the results from the pseudophakic patients were more variable, there is some evidence to suggest that epikeratophakia provides inferior visual function to contact lens correction or intraocular lens implantation. The results also suggest that the measurement of visual acuity in the presence of glare fails to identify many patients with a functional visual impairment secondary to glare.
\end{abstract}

The standard methods of correcting aphakia with either a contact lens or an intraocular lens implant, can both result in subjectively good vision and good Snellen acuity. ${ }^{1-3}$ Recent reports of aphakic patients corrected with epikeratophakia have also emphasised the potential for good visual acuity following this procedure. ${ }^{4-7}$ However, the limitations of Snellen acuity in the assessment of visual performance are now widely recognised. Contrast sensitivity measurement provides an additional means of evaluating visual performance, with further information being given if these tests are also performed in the presence of glare. ${ }^{8-12}$

There have been several reports on contrast sensitivity in aphakia and pseudophakia ${ }^{13-19}$ although the results have shown some variability. This is probably partly related to patient selection criteria and to different methodological approaches. While some investigators have found contrast sensitivity losses in pseudophakic patients compared with age matched controls ${ }^{15,17}$ others found no such loss. ${ }^{16,18}$

There has been little emphasis on monitoring contrast sensitivity in aphakic patients corrected with epikeratophakia, although Justin et $a l^{20}$ have reported depressed contrast sensitivity three months post-operatively, especially at intermediate spatial frequencies. Repeat measurements at six to twelve months post-operatively showed an improved performance, although contrast sensitivity still remained depressed relative to the pre-operative results.

The aim of this study was to investigate the effect of glare on contrast sensitivity and Snellen acuity in patients who had aphakia corrected by one of three methods; contact

From: Moorfields Eye Hospital and Institute of Ophthalmology, University of London.

Correspondence: R. A. Harper BSc MBCO, Visual Science Unit, Radcliffe Infirmary, Woodstock Road, Oxford OX2 $6 \mathrm{HE}$. 
lens, epikeratophakia or intraocular lens implant.

\section{Materials and Methods}

Twelve unilaterally aphakic patients were selected from the clinics at Moorfields Eye Hospital. A paired eye design was used. ${ }^{21}$ These patients all had normal fellow eyes to act as a control, as it is known that the within subject variance for contrast sensitivity measurements in such patients is typically less than the between subject variance. ${ }^{17}$ An additional patient who was pseudophakic in one eye and had an epikeratophakia lens in the other was also included.

All patients were tested at least three months post surgery and had a corrected visual acuity in each eye of $6 / 9$ or better. Patients with any additional ocular pathology were excluded from the study except that the fellow eye of one patient had early cataract, although visual acuity was still 6/6. Of the twelve unilateral aphakes, four patients were corrected with hard contact lenses, four with epikeratophakia lenses and four patients were pseudophakic with posterior chamber lenses. (One patient with epikeratophakia subsequently had the donor lenticule removed due to high anisometropia and had a secondary intraocular lens implanted).

A Brightness Acuity Tester (Mentor Inc) was used as a glare source. This consisted of an illuminated hemispherical bowl, $60 \mathrm{~mm}$ in diameter, with a central $12 \mathrm{~mm}$ circular aperture through which the patients viewed the gratings or letter chart. The bowl luminance was $300 \mathrm{~cd} / \mathrm{m}^{2}$. Visual acuity was measured using an internally illuminated Snellen chart. All patients had pupil diameters recorded with a pupil gauge in ambient room illumination.

Vertical sinewave gratings were computer generated on the screen of a Tektronix 608 monitor (P31 standard phosphor). The screen measured $9 \mathrm{~cm}$ by $11 \mathrm{~cm}$ at a viewing distance of $1.5 \mathrm{~m}$. The space averaged screen luminance was $14 \mathrm{~cd} / \mathrm{m}^{2}$. All patients wore the appropriate spectacle correction. Contrast thresholds were measured for seven different spatial frequencies, 0.5, 1.0, 2.0, 4.0, 8.0, 16 and 30 cycles per degree. After an initial demonstration to each patient, each eye was tested, with and without the glare source, with a 0.5 second exposure of a stationary grating to which the patient responded by pressing a 'yes' button (the grating was detected) or 'no' button (the grating was not detected) following an auditory prompt. Testing was continued at each spatial frequency, using the method of constant stimuli, with a staircase procedure continued to four reversals.

\section{Results}

Table I provides clinical data on the patients. In the presence of glare, Snellen acuity only decreased in two out of the total of 26 eyes; in one epikeratophakia eye (patient 13) and one eye with early cataract (patient 12). In each of these two cases the glare source reduced the acuity by one line on the Snellen chart. Pupil diameters ranged from two to seven $\mathrm{mm}$, but in no case did the interocular difference exceed $1 \mathrm{~mm}$.

Figures 1-4 show contrast sensitivity and threshold elevation curves for all the patients. For each patient four contrast sensitivity curves are shown; results for each eye are shown with and without the glare source. Below the contrast sensitivity curves two threshold elevation curves are shown for the conditions with and without glare. These curves plot the ratio of the operated eye's contrast threshold to that of the normal fellow eye at each spatial frequency. Ordinate values of zero (dashed lines) indicate equality of the operated eye with the patient's normal eye and increasing positive values indicate reduction in contrast sensitivity in that eye relative to the normal fellow eye.

Figure 1 illustrates the contrast sensitivity results for the contact lens patients. There was a relative depression in contrast sensitivity in the contact lens eyes at nearly all of the points plotted. Two patients (1 and 2 ) show accentuation of this effect with increasing spatial frequency, especially in the presence of glare.

Figure 2 illustrates the contrast sensitivity results for the epikeratophakia patients. The threshold elevation curves show that there was a marked relative depression in contrast sensitivity in the epikeratophakia eyes at all spatial frequencies for all patients. This effect tended to be greater at the higher spatial frequencies (patients 5, 6 and 8) and more accen- 
Table I Clinical data for all patients

\begin{tabular}{|c|c|c|c|c|c|c|c|c|}
\hline \multirow[b]{2}{*}{ Patient } & \multirow{2}{*}{$\begin{array}{c}\text { Age } \\
\text { (years) }\end{array}$} & \multirow{2}{*}{$\begin{array}{l}\text { Time from } \\
\text { surgery } \\
\text { (months) }\end{array}$} & \multicolumn{3}{|c|}{ Operated eye } & \multicolumn{3}{|c|}{ Fellow eye } \\
\hline & & & Status & $V A$ & $V A g$ & Status & $V A$ & $V A g$ \\
\hline 1 & 39 & 24 & CL & $6 / 5$ & $6 / 5$ & NORM & $6 / 5$ & $6 / 5$ \\
\hline 2 & 21 & 8 & $\mathrm{CL}$ & $6 / 5$ & $6 / 5$ & NORM & $6 / 5$ & $6 / 5$ \\
\hline 3 & 15 & 8 & $\mathrm{CL}$ & $6 / 5$ & $6 / 5$ & NORM & $6 / 5$ & $6 / 5$ \\
\hline 4 & 26 & $>24$ & $\mathrm{CL}$ & $6 / 6$ & $6 / 6$ & NORM & $6 / 5$ & $6 / 5$ \\
\hline 5 & 28 & 12 & EPI & $6 / 9$ & $6 / 9$ & NORM & $6 / 5$ & $6 / 5$ \\
\hline 6 & 10 & 8 & EPI & $6 / 9$ & $6 / 9$ & NORM & $6 / 5$ & $6 / 5$ \\
\hline 7 & 39 & 5 & EPI & $6 / 6$ & $6 / 6$ & NORM & $6 / 5$ & $6 / 5$ \\
\hline 8 & 21 & 5 & EPI & $6 / 9$ & $6 / 9$ & NORM & $6 / 5$ & $6 / 5$ \\
\hline 9 & 64 & 11 & IOL & $6 / 5$ & $6 / 5$ & NORM & $6 / 5$ & $6 / 5$ \\
\hline 10 & 72 & 3 & IOL & $6 / 5$ & $6 / 5$ & NORM & $6 / 5$ & $6 / 5$ \\
\hline 11 & 24 & 10 & IOL & $6 / 5$ & $6 / 5$ & NORM & $6 / 5$ & $6 / 5$ \\
\hline 12 & 67 & 10 & IOL & $6 / 5$ & $6 / 5$ & CAT & $6 / 6$ & $6 / 9$ \\
\hline 13 & 60 & 17 & IOL & $6 / 9$ & $6 / 9$ & EPI & $6 / 9$ & $6 / 12$ \\
\hline
\end{tabular}

$\mathrm{CL}=$ contact lens correction, $\mathrm{EPI}=$ epikeratophakia, $\mathrm{IOL}=$ intraocular lens, $\mathrm{NORM}=$ normal phakic eye $\mathrm{CAT}=$ cataract, $\mathrm{VAg}=$ visual acuity measured with glare. For patient 7 the epikeratophakia lens was subsequently removed and a secondary IOL was implanted (where the visual acuity was $6 / 5$ with and without glare.)

tuated in the presence of glare (patients 5, 6 and 7).

In the presence of glare, for the epikeratophakia and contact lens patients combined, there was significantly greater depression in mean contrast sensitivity (averaged over all spatial frequencies) in the operated eyes relative to the fellow eyes (Wilcoxan test for paired samples, $\mathrm{p}<0.05$ ).

In the absence of glare, this mean depression in contrast sensitivity in operated eyes relative to fellow eyes, was significantly greater for epikeratophakia than for contact lens corrected aphakia (Wilcoxan test for unpaired samples, $\mathrm{p}<0.05$ ).

Figure 3 illustrates the contrast sensitivity results for pseudophakic patients. Two patients (9 and 10) showed relatively little difference in contrast sensitivity between the operated and normal eyes when the results over all spatial frequencies are considered. One patient (11), (who was only tested without glare) showed a marked depression in contrast sensitivity in the operated eye compared with the fellow eye especially at higher spatial frequency. Patient 12 , who had early posterior subcapsular cataract in the fellow eye, showed a large relative elevation of contrast sensitivity in the operated eye (i.e. a reduction in sensitivity in the cataractous eye) especially at the higher spatial frequencies. This was accentuated in the presence of glare.

Figure 4a illustrates the contrast sensitivity results for patient 13 who was pseudophakic in one eye and was corrected with an epikeratophakia lens in the other eye. There was a definite loss of contrast sensitivity in the epikeratophakic eye, relative to the pseudophakic eye and this effect was more marked at higher spatial frequencies. Figure 4b illustrates the contrast sensitivity results for patient 7 (operated eye only) who had the epikeratophakia lens removed and a secondary intraocular lens implanted. Without glare there is little difference in performance between the epikeratophakia procedure and the secondary intraocular lens, except at 0.50 cycles/degree where contrast sensitivity is lower with epikeratophakia. With glare there is some indication of poorer performance with the epikeratophakia procedure relative to the intraocular lens implant.

\section{Discussion}

In spite of relatively good visual acuity and apparently satisfactory surgical results, there was a marked reduction in contrast sensitivity in the epikeratophakia and contact lens corrected eyes (relative to fellow eyes). Glare accentuated this loss of sensitivity, especially in the patients with epikeratophakia. Contrast 

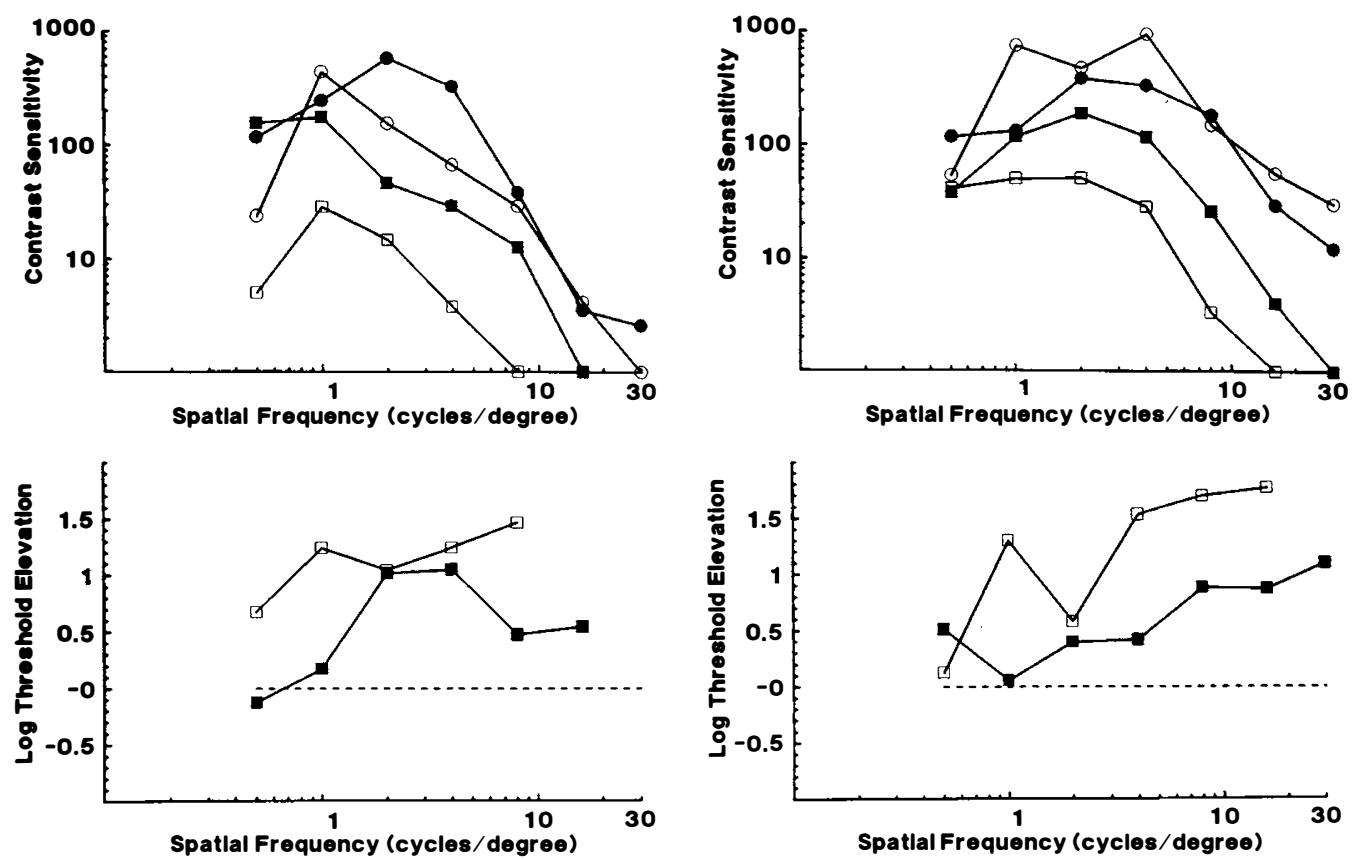

Fig. 1a

Fig. $1 b$
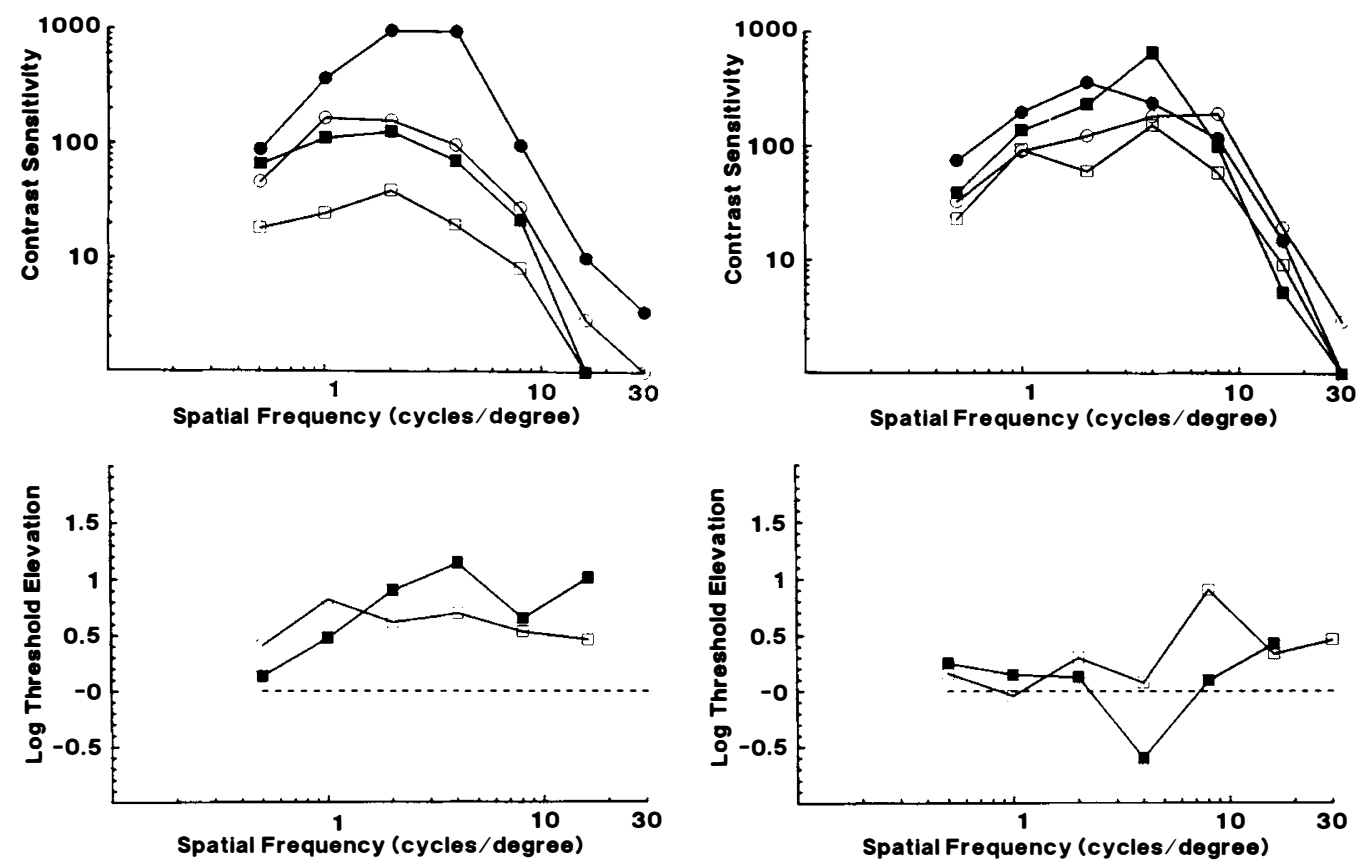

Fig. 1c

Fig. 1d

Fig. 1 (a-d) Illustrates the contrast sensitivity functions (CSF) for patients 1-4 (contact lens corrected aphakes) respectively. (Circles represent normal eyes and squares represent operated eyes.) Two curves are shown for each eye. (Closed symbols represent measurements made without glare and open symbols represent measurements made with glare.) The two log threshold elevation curves shown beneath the CSFs plot the ratio of the operated eye's contrast threshold relative to the normal eye at each spatial frequency. (Closed squares represent measurements made without glare and open squares represent measurements made with glare.) 

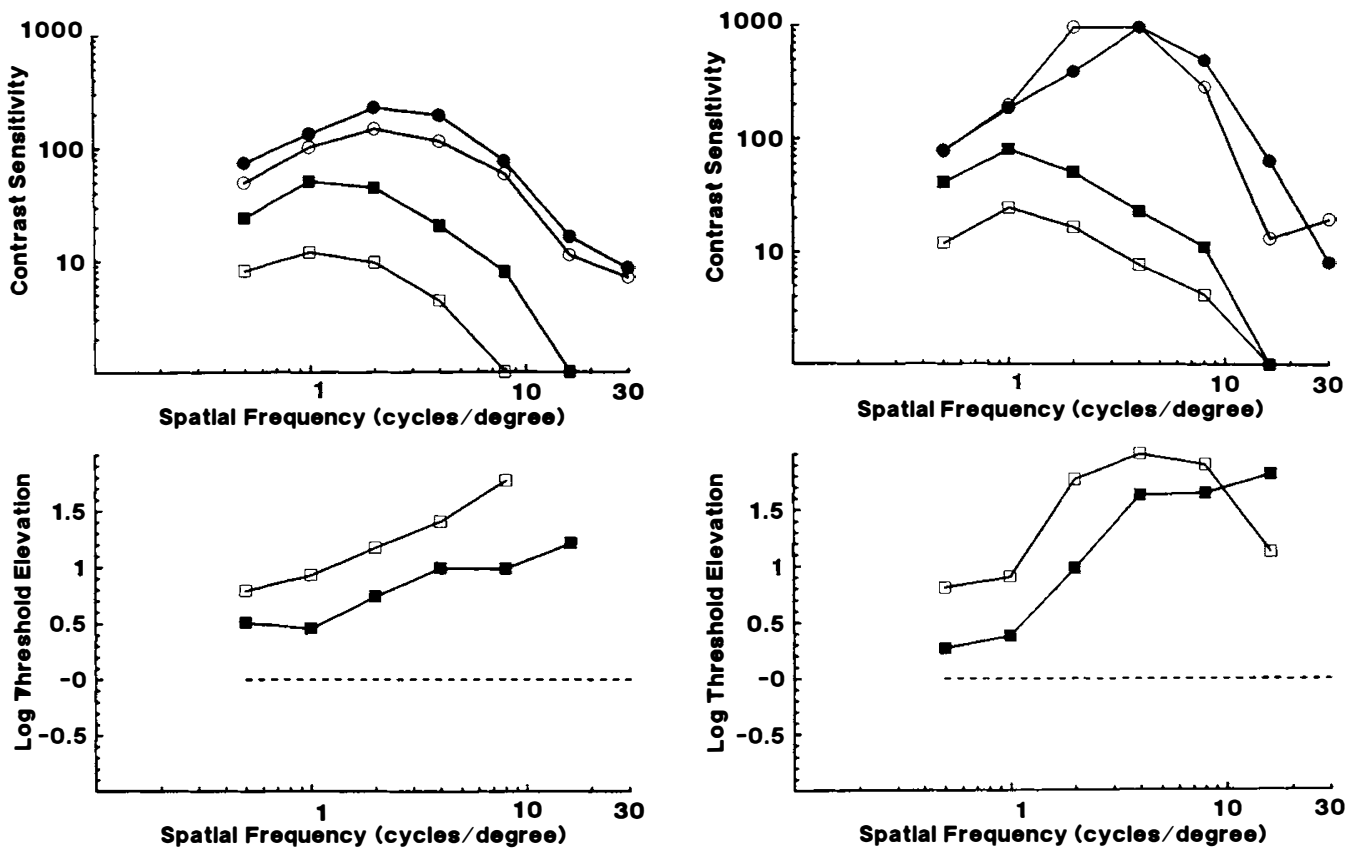

Fig. 2a

Fig. 2b
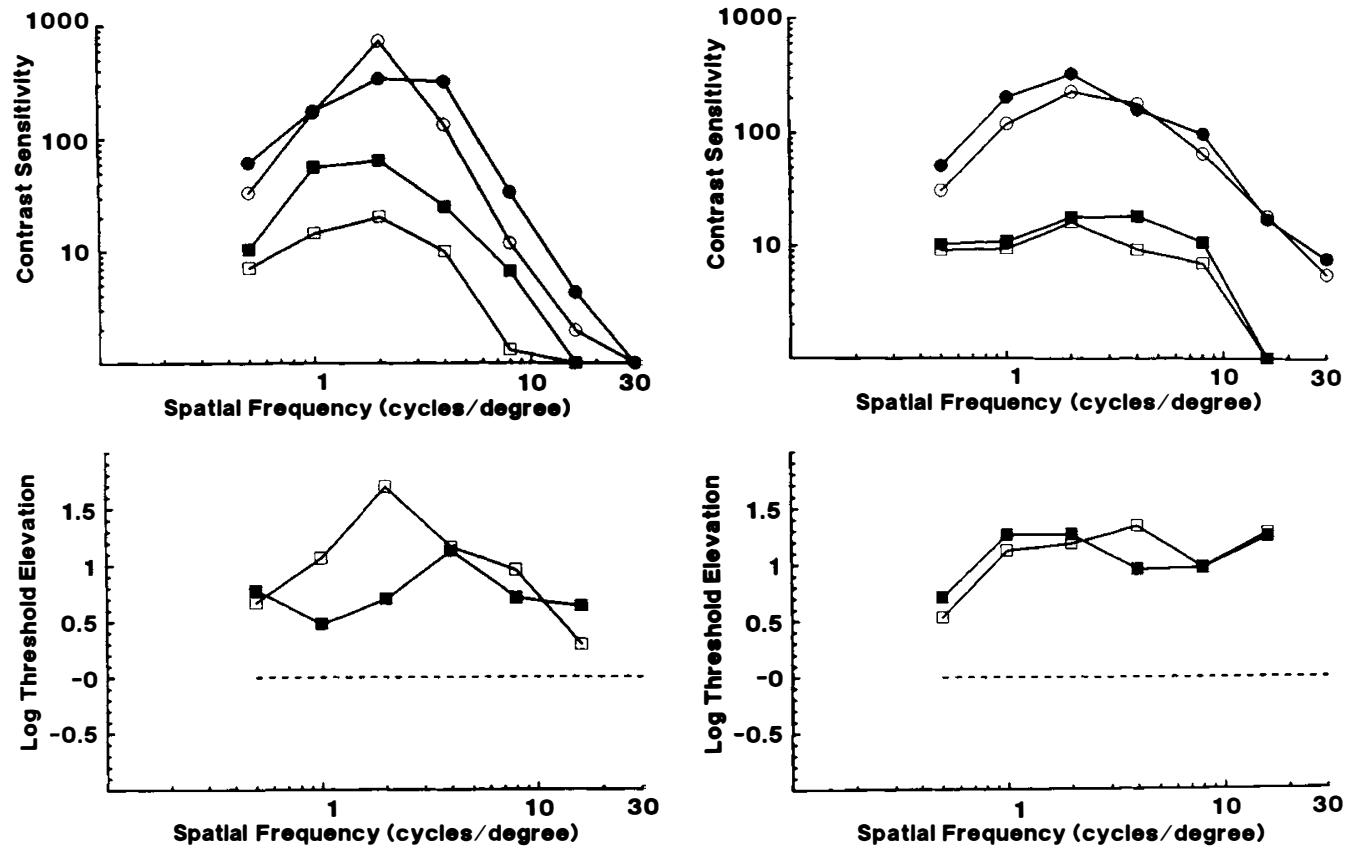

Fig. 2c

Fig. 2d

Fig. 2 (a-d) Illustrates the contrast sensitivity functions (CSF) for patients 5-8 (epikeratophakia) respectively. (Circles represent normal eyes and squares represent operated eyes.) Two curves are shown for each eye. (Closed symbols represent measurements made without glare and open symbols represent measurements made with glare.) The two log threshold elevation curves shown beneath the CSFs plot the ratio of the operated eye's contrast threshold relative to the normal eye at each spatial frequency. (Closed squares represent measurements made without glare and open squares represent measurements made with glare.) 

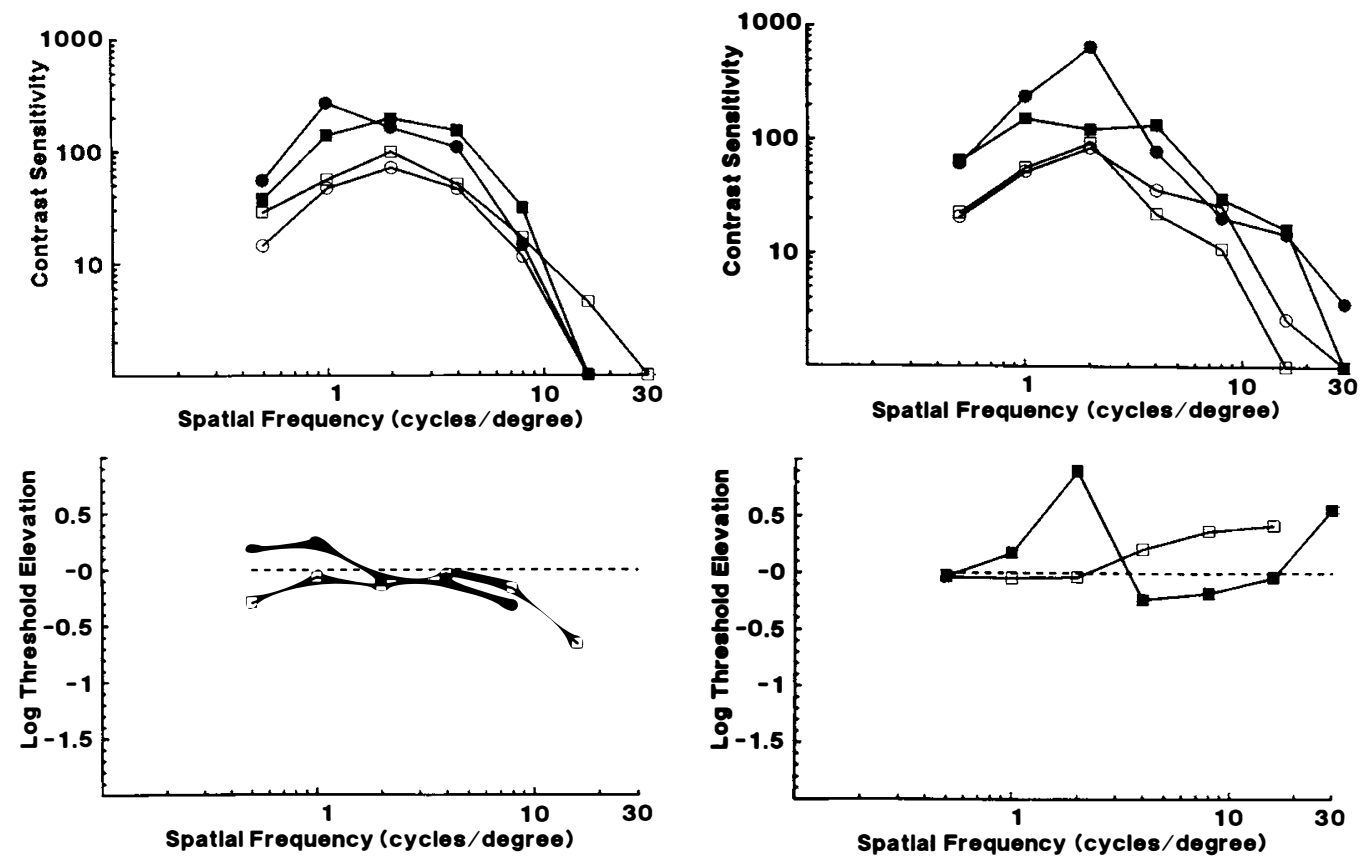

Fig. 3a

Fig. 3b
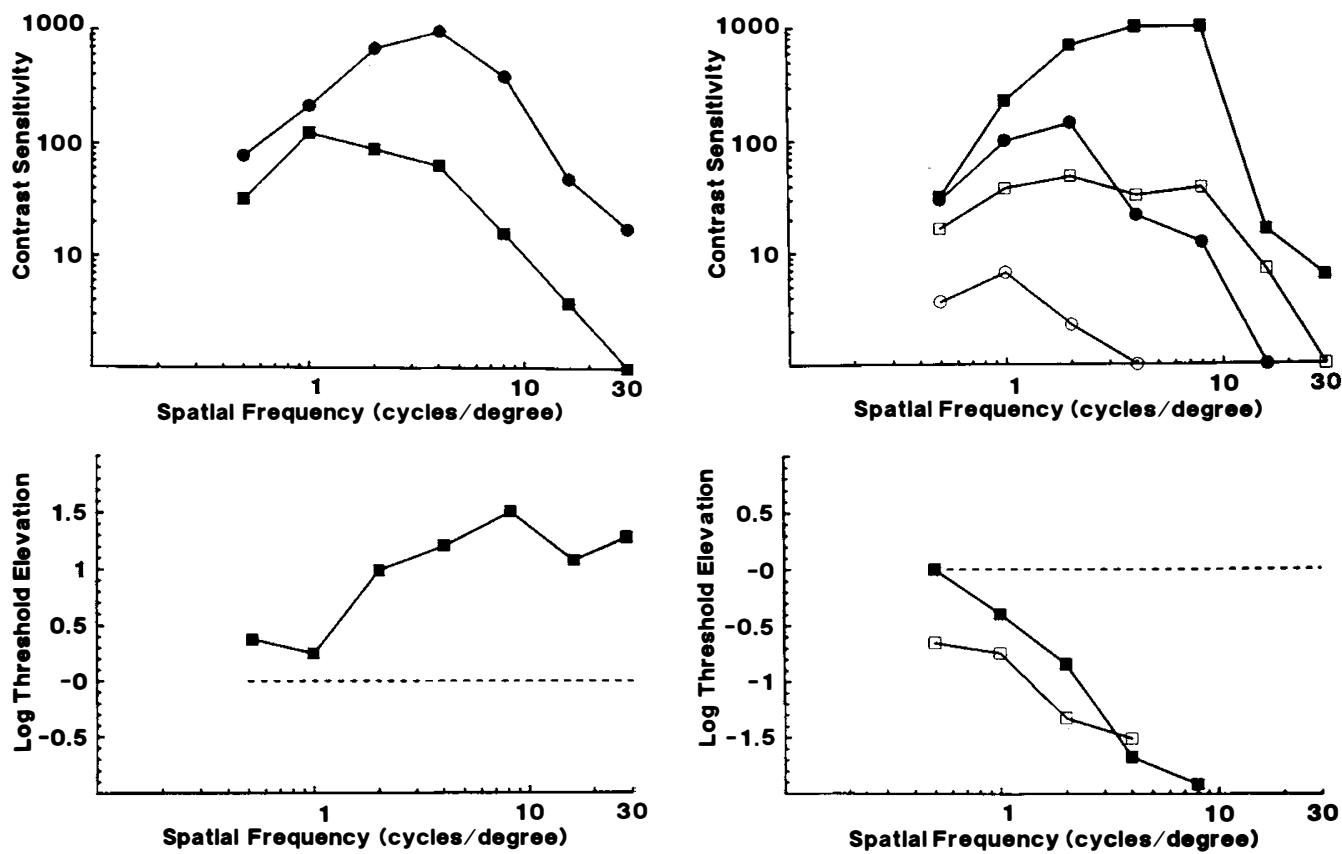

Fig. 3c

Fig. 3d

Fig. 3 (a-d) Illustrates the contrast sensitivity functions (CSF) for patients 9-12 (pseudophakia) respectively. (Circles represent normal eyes and squares represent operated eyes.) Two curves are shown for each eye, except patient 11 (without glare test condition only). (Closed symbols represent measurements made without glare and open symbols represent measurements made with glare.) The two log threshold elevation curves shown beneath the CSFs plot the ratio of the operated eye's contrast threshold relative to the normal eye at each spatial frequency. (Closed squares represent measurements made without glare and open squares represent measurements made with glare.) 

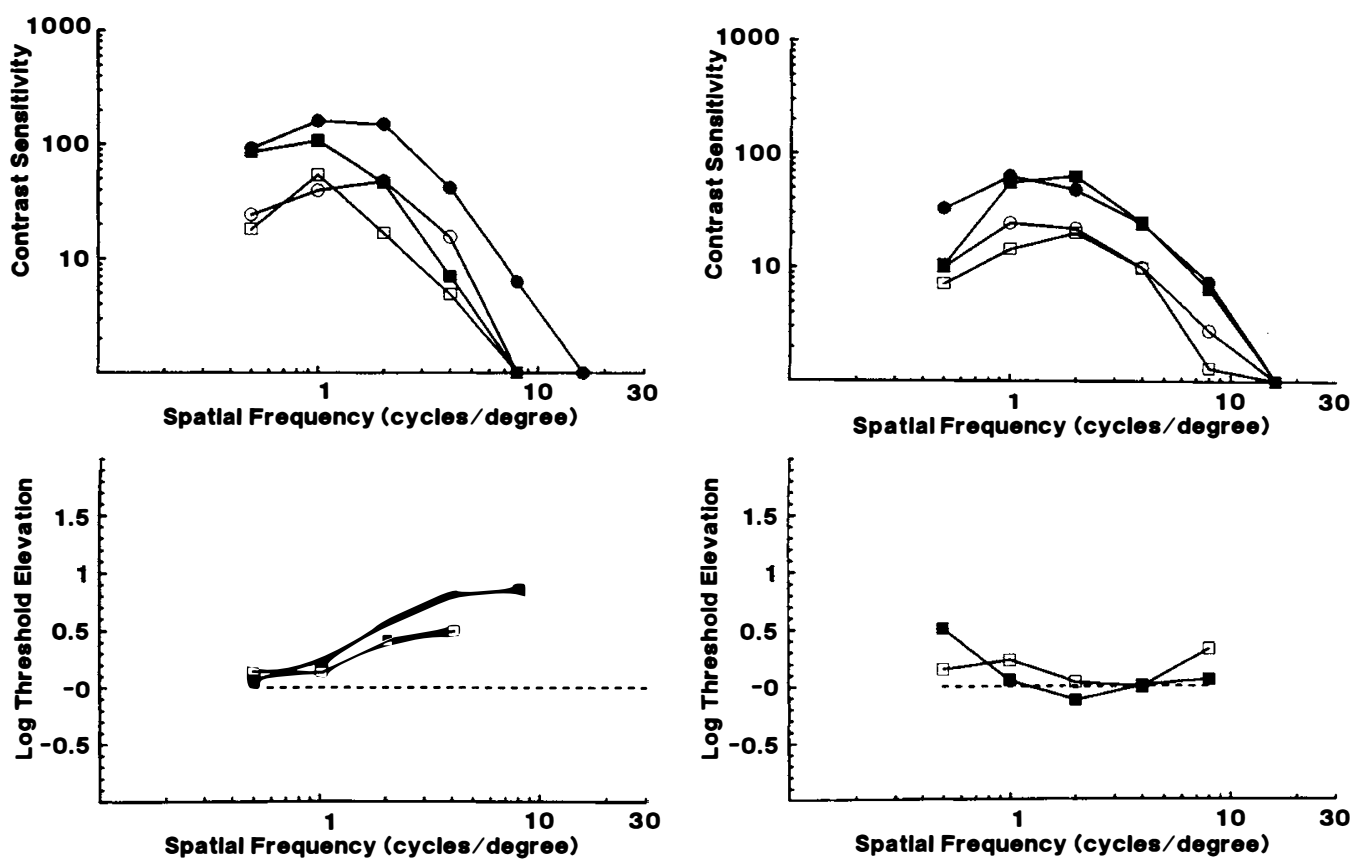

Fig. 4a

Fig. 4b

Fig. 4 (a-b) Illustrates the contrast sensitivity functions for patients 13 and 7 respectively. Patient 13 was epikeratophakic in one eye (squares) and pseudophakic in the fellow eye (circles). Patient 7 had the epikeratophakia lens (squares) removed and a secondary intraocular lens (circles) was implanted. (Closed symbols represent measurements made without glare and open symbols represent measurements made with glare.) The two log threshold elevation curves plot the ratio of the epikeratophakia eye's contrast threshold relative to the pseudophakia eye at each spatial frequency. (Closed squares represent measurements made without glare and open squares represent measurements made with glare.)

sensitivity results in the pseudophakic group were more variable. Whereas most operated eyes corrected with contact lens or epikeratophakia showed a reduction in contrast sensitivity when compared to the fellow eye, in the pseudophakic group one patient showed a superiority of the operated eye over the fellow eye (patient 12) and two patients showed approximate equivalence between their operated and fellow eyes (patients 9 and $10)$. It is likely that the relatively good performance of the operated eye in these three cases was due to the relatively poorer performance of the fellow eye secondary to senile lens changes. The single pseudophakic patient who did show a definite contrast sensitivity reduction in the operated eye (patient 11) was 24 years old. In contrast, patients 9,10 and 12 were over 64 years old and one of these (patient 12) had clinically apparent cataract.

Although Snellen acuity testing identified three of the four epikeratophakia patients as having reduced visual performance (i.e. the visual acuity of the epikeratophakia eye was $6 / 9$ only) it failed to identify any difference between normal and operated eyes in the contact lens group. However, contrast sensitivity testing showed marked deficits in all epikeratophakia patients and also indicated relatively reduced visual function in three out of the four contact lens corrected eyes compared to their fellows. Even in the presence of glare, visual acuity measurements on the Snellen chart showed no deficit in 24 out of the 26 eyes tested, reducing acuity by one line only in one epikeratophakia eye and one eye with early cataract. However, while Snellen acuity testing identified only two eyes with reduced visual performance secondary to glare, contrast sensitivity measurements showed deficits in all operated eyes and in most normal eyes. These results highlight the inadequacy of the 
assessment of visual performance and glare disability by the measurement of visual acuity alone. The poor discriminatory potential of the Snellen chart may be partially due to its design. The chart was truncated beyond $6 / 5$ and so would not necessarily have identified a real difference in acuity that may have existed with the glare source. However, while a standard Snellen chart has limitations for accurate clinical research, ${ }^{22-24}$ it is still used in most clinical situations.

Attempts have been made to predict the identification of complex objects, such as Snellen letters, from the contrast sensitivity function. ${ }^{25}$ Although Snellen letter acuity and contrast sensitivity are both measures of threshold spatial vision, visual acuity measures an extensity threshold (the minimum sized target that can be resolved or recognised), whereas contrast sensitivity measures an intensity threshold (the minimum luminance difference that can be detected). Thus the two tests do not measure the same underlying ability. As glare is due to the contrast lowering effect of intraocular light scatter, creating a veiling luminance superimposed on the retinal image, it has a marked effect on contrast thresholds, although high contrast Snellen letters may still be detected and recognised, even in the presence of reduced contrast.

Our results suggest that the measurement of visual acuity in the presence of glare using a standard Snellen chart, as has been suggested $^{26.27}$ will not necessarily identify many patients with a functional visual impairment secondary to glare. Thus, although the Brightness Acuity Tester may well be able to predict outdoor visual acuity ${ }^{26.28}$ it is unlikely to detect all patients with visual loss secondary to glare.

These relative threshold contrast sensitivity losses, which often exceeded 1 log unit, are likely to be practically important, as any loss of contrast sensitivity at threshold will similarly effect suprathreshold performance ${ }^{15.29}$ and reduced contrast sensitivity at low spatial frequencies may have important visual significance..$^{30.31}$ Additionally, recent evidence suggests that reduced monocular contrast sensitivity may reduce binocular performance due to binocular inhibition. ${ }^{32}$ The results from the unilaterally aphakic patients suggest that epikeratophakia provides inferior visual function to that obtained from contact lens correction. In this study evaluation of pseudophakia is complicated by the possibility of early cataract in the fellow eyes. However, patients 7 and 13 provided a direct comparison between epikeratophakia and pseudophakia. For patient 7 , there was some indication of poorer performance with the initial epikeratophakia procedure, relative to subsequent intraocular lens implantation. Patient 13 had an acuity of $6 / 9$ in each eye, yet even in the absence of glare the contrast sensitivity was depressed in the epikeratophakia eye.

The results of this study have confirmed that the restoration of good visual acuity following cataract surgery does not necessarily indicate normal visual function. Reduced contrast sensitivity may have important implications for everyday visual tasks and job performance. Therefore where alternative means of visual correction are available, consideration should not only be given to the relative safety and convenience of such corrections, but also to their visual quality.

\section{References}

${ }^{1}$ Clayman HM, Jaffe NS, Jaffe MS, Luscombe SM: Bilateral intraocular lens implantation. Ophthalmology 1983, 90: 321-3.

${ }^{2}$ Kraff MC, Sanders DR, Lieberman HL, Kraff J: Secondary intraocular lens implantation. Ophthalmology 1983, 90: 324-6.

${ }^{3}$ Stark WJ, Leske MC, Worthan DM, Murray GC: Trends in cataract surgery and intraocular lens implantation in the United States. $A m J$ Ophthalmol 1983, 96: 304-10.

${ }^{4}$ Morgan KS, McDonald MB, Hiles DA et al: The nationwide study of epikeratophakia for aphakia in children. Am J Ophthalmol 1987, 103: 366-74.

${ }^{5}$ Durrie DS, Habrich DL, Dietze TR: Secondary intraocular lens implantation $v s$ epikeratophakia for the treatment of aphakia. Am J Ophthalmol 1987, 103: 384-91.

${ }^{6}$ Lass JH, Stocker EG, Fritz ME, Collie DM: The surgical correction of aphakia, myopia and keratoconnus. Ophthalmology 1987, 94: 912-25.

${ }^{7}$ Kelly CG, Keates RH, Lembach RG: Epikeratophakia for pediatric aphakia. Arch Ophthalmol 1986, 104: 680-2.

${ }^{8}$ Paulsson LE and Sjöstrand J: Contrast sensitivity in the presence of a glare light. Invest Ophthalmol Vis Sci 1980, 19: 401-6.

${ }^{9}$ Atkin A, Asbell P, Justin N, Smith H, Wayne R, Winterkorn J: Radial keratotomy and glare 
effects on contrast sensitivity. Doc Ophthalmol 1986, 62: 129-48.

${ }^{10}$ Abrahamsson $\mathrm{M}$ and Sjöstrand $\mathrm{J}$ : Impairment of contrast sensitivity function (CSF) as a measure of disability glare. Invest Ophthalmol Vis Sci 1986, 27: 1131-6.

11 Trick LR and Hartstein J: Investigation of contrast sensitivity following radial keratotomy. Ann Ophthalmol 1987, 19: 251-4.

${ }^{12}$ Elliott DB, Gilchrist J, Whitaker D: Contrast sensitivity and glare sensitivity changes with three types of cataract morphology: are these techniques necessary in a clinical evaluation of cataract? Ophthal Physiol Opt 1989, 9: 25-30.

${ }^{13}$ Enoch JM, Yamade S, Namba A: Contrast (modulation) sensitivity functions measured in patients with high refractive error with emphasis on aphakia: II determinations on patients. Doc Ophthalmol 1979, 47: 147-62.

${ }^{14}$ Guillon $\mathrm{M}$ and Bleshoy $\mathrm{H}$ : Comparative study of the visual performance of various aphakic corrections. Acta Ophthalmol 1983, 61: 851-9.

${ }^{15}$ Hess RF, Woo G, White PD: Contrast attenuation characteristics of iris clipped intraocular lens implants in situ. Br J Ophthalmol 1985, 69: 12935 .

${ }^{16}$ Owsley C, Gardiner T, Sekuler R, Leiberman H: Role of the crystalline lens in the spatial vision loss of the elderly. Invest Ophthalmol Vis Sci 1985, 26: 1165-70.

${ }^{17}$ Weatherill $\mathrm{J}$ and Yap M: Contrast sensitivity in pseudophakia and aphakia. Ophthalmol Physiol Opt 1986, 6: 297-301.

${ }^{18}$ Hammer HM, Yap M, Weatherill JR: Visual performance in pseudophakia with standard and ultraviolet-absorbing intraocular lenses: A preliminary report. Trans Ophthalmol Soc UK 1986, 105: 441-6.

${ }^{19}$ Roel L, Zemon V, Jindra LF, Peralta M, Mittl M: Contrast sensitivity and Snellen acuity of patients with intraocular lens implants. Invest Ophthalmol Vis Sci 1988, (ARVO suppl): 434.
${ }^{20}$ Justin N, Asbell P, Freidman A: Glare and contrast sensitivity testing in epikeratoplasty. Invest Ophthalmol Vis Sci 1987, (ARVO suppl): 225.

${ }^{21}$ Ray WA and O'Day DM: Statistical analysis of multi-eye data in ophthalmic research. Invest Ophthalmol Vis Sci 1985, 26: 1186-8.

${ }^{22}$ Wild JM and Hussey MK: Some statistical concepts in the analysis of vision and visual acuity. Ophthal Physiol Opt 1985, 5: 63-71.

${ }^{23}$ Lovie-Kitchin JE: Validity and reliability of visual acuity measurements. Ophthalmol Physiol Opt 1988, 8: 363-70.

${ }^{24}$ Elliott DB and Sheridan M: The use of Accurate visual acuity measurements in clinical anti-cataract formulation trials. Ophthal Physiol Opt 1988, 8: $397-401$.

${ }^{25}$ Gstalder R and Green DG: Laser interferometric acuity in amblyopia. J Pediatr Ophthalmol 1971, 8: 251-65.

${ }^{26}$ Holladay J, Prager TC, Trujillo J, Ruiz RS: Brightness Acuity Test and outdoor visual acuity in cataract patients. J Cataract Refract Surg 1987, 13: 67-9.

${ }^{27}$ Maltzman BA, Horan C, Rengel A: Penlight test for glare disability of cataracts. Ophthalmic Surg 1988, 19: 356-8.

${ }^{28}$ Neumann AC, McCarty GR, Locke J, Cobb B: Glare disability devices for cataractous eyes: A consumers' guide. J Cataract Refract Surg 1988, 14: $212-6$.

${ }^{29}$ Ginsburg AP: Spatial filtering and vision. In Proenza M, Enoch JM, Jampolsky A eds. Clinical Applications of Visual Psychophysics. Cambridge: Cambridge University Press 1981: 70-106.

${ }^{30}$ Hess RF and Woo G: Vision through cataracts. Invest Ophthalmol Vis Sci 1978, 17: 428-34.

31 Owsley $C$ and Sloan ME: Contrast sensitivity acuity, and the perception of real world targets. $\mathrm{Br} J$ Ophthalmol 1987, 71: 791-6.

32 Pardhan S, Gilchrist J, Douthwaite W: The effect of spatial frequency on binocular contrast inhibition. Ophthal Physiol Opt 1989, 9: 46-9. 